\title{
Prednisolone Induced Systemic Toxicity in Case of Steroid Sensitive Nephrotic Syndrome
}

\author{
Nishi Sheth*, Dhruv Zaveri, Hemraj Singh Rajput \\ Department of Pharmacy, Sumandeep Vidyapeeth (Deemed to be University), Piparia, Waghodia, Vadodara, Gujarat, INDIA.
}

\begin{abstract}
Prednisolone is a corticosteroid, it works on immune system to relieve swelling, redness, and inflammation.it is a choice of drug for arthritis, cancer, asthma, allergic condition, bell's palsy, Nephrotic syndrome and disorders of endocrine system. Prednisolone helps decreasing inflammation by suppression of leukocytes and decrease expression of pro-inflammatory markers. Nephrotic syndrome is a condition in which damage kidney glomeruli which leaks protein into urine from blood. In pediatric population the choice of drug selected is prednisolone which resolves the symptoms and reduces infection. Prednisolone is the drug considered for the frequently relapsing Nephrotic syndrome. It should be given on alternate basis. for patient with infrequent relapses, therapy should be not prolonged. Adverse effects of prednisolone are hypertension, adrenal suppression, osteoporosis, diabetes mellitus, poor growth and cushingoid syndrome. Systemic toxicity due to prednisolone in pediatric patient increases the risk of infection and pre-renal failure. In this case report, it is summarized that despite of everyday prednisolone intake, alternate day therapy is more effective and causes less side effects. Proper monitoring is necessary and timely laboratory findings should be obtained for less adverse events.
\end{abstract}

Key words: Prednisolone, Toxicity, Nephrotic syndrome, Adverse drug reaction, Pre-renal failure.

\section{INTRODUCTION}

Nephrotic syndrome is a kidney disorder that damage glomeruli in kidney which result in protein excretion into the urine. The prevalence is found to be $2-7$ cases per 1,00,000 children. Symptoms usually seen are pitting edema, Edema found over lower extremities, face, periorbital regions, scrotum and abdomen, hematuria, hypotension, weight gain, decreased appetite, Fatigue, Ascites (fluid buildup in belly area) and hypertension. Nephrotic syndrome in child is seen at age of 2-5 years. Mostly the treatment consists of steroids and immunosuppressant's with appropriate medical advice. Prednisolone is corticosteroid, it works on immune system to relieve swelling, redness, and inflammation. It is a choice of drug for nephrotic syndrome. It has many actions which induce inflammatory response. Prednisolone exert their antiinflammatory effect by inducing apoptosis of lymphoid cells, promoting expression of anti-inflammatory protein and interrupting cytokine mediated inflammatory pathways. Food and Drug Administration (FDA) uses of prednisolone in Nephrotic syndrome is indicated to decrease proteinuria without uremia in pediatric as well as adult. NonFDA uses of prednisolone are in COPD (Chronic obstructive pulmonary disease), Bell's palsy, and Nephropathy. Adverse drug reaction (ADR) of prednisolone can be seen in patients who are taking orally since long period of time (Table 1). Most reported ADR is fluid retention. Monitoring parameters for prednisolone depends upon from the time being it is taken. In child, Growth should be monitored properly. In patients with prolonged therapy ophthalmic examination must be warranted. Especially with prolonged oral formulation. Sign of new infections should be checked in relapse of Nephrotic syndrome. The dosing should be done on the basis of BSA (30kg or less) 2 $\mathrm{mg} / \mathrm{kg}$ daily in 2 divided doses for 2 weeks, followed by $1.5 \mathrm{mg} / \mathrm{kg}$ on every alternate day. 24-hr calcium and creatinine should be done for patient taking from more than 4 weeks. Routine laboratory test and post prandial blood glucose should be done at regular basis. ${ }^{1}$
DOI: 10.5530/ijopp.14.3.47

\section{Address for} correspondence: Ms. Nishi Sheth Student of Pharm D., Department of Pharmacy, Sumandeep Vidyapeeth Deemed to be University, Piparia, Vadodara-391 760, Gujarat, INDIA.

Email Id: nishisheth72@gmail. com

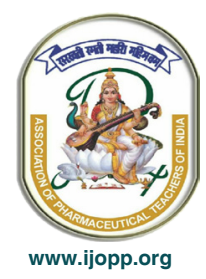




\section{CHRONIC ADMINISTRATION OF PREDNISOLONE}

During long term administration of prednisolone, growth suppression, adrenal suppression, hyperglycemia, Cushing syndrome and fluid retention are seen. After assessment of long-term administration of prednisolone, baseline measure should be taken like laboratory assessment with complete blood count, blood glucose and renal function should be checked. Patient with relapsing nephrotic syndrome should be checked for any serious infections. ${ }^{2}$

\section{CASE}

A 5-year-old patient came to multispecialty hospital with complaints of swelling of face, abdomen, scrotum and lower limbs in the last 8 days (Figure 1). Abdominal distension in the last 8-10 days, diurnal variation more in morning, pedal edema and penile swelling. He was already a $(2 \mathrm{mg} / \mathrm{kg} /$ day $)$ of which tapering was to be done to $1.5 \mathrm{mg} / \mathrm{kg}$ every alternate day. Plan was to tapper prednisolone but patient continued to take 10 $\mathrm{mg}$ daily instead of tapering and stopping. Facial edema, generalized edema, B/L pedal edema, penile swelling and abdominal distension was observed. On examination, urine test were found abnormal. High amount of albumin was found in urine. Due to severe toxicity of

\begin{tabular}{|c|c|}
\hline CVS & $\begin{array}{l}\text { Body fluid retention, bradyarrhythmia } \\
\text { Hypertension }\end{array}$ \\
\hline Dermatologic & $\begin{array}{c}\text { Acne, Diaphoresis, Fragile skin, Steven- } \\
\text { Johnson syndrome }\end{array}$ \\
\hline $\begin{array}{l}\text { Endocrine/ } \\
\text { metabolic effect }\end{array}$ & $\begin{array}{l}\text { Decreased body growth, hyperuricemia, } \\
\text { hyperglycemia, hypokalemia. }\end{array}$ \\
\hline $\begin{array}{l}\text { Gastrointestinal } \\
\text { effects }\end{array}$ & Gastrointestinal ulcer, swollen abdomen \\
\hline $\begin{array}{l}\text { Hematologic } \\
\text { effects }\end{array}$ & $\begin{array}{l}\text { Agranulocytosis, lymphocytopenia, } \\
\text { monocytopenia }\end{array}$ \\
\hline Hepatic effects & Hepatotoxicity \\
\hline $\begin{array}{l}\text { Immunologic } \\
\text { effects }\end{array}$ & Hypersensitivity reaction \\
\hline Musculoskeletal & $\begin{array}{l}\text { Aseptic necrosis of bone, osteoporosis, drug } \\
\text { induced myopathy, muscle weakness. }\end{array}$ \\
\hline $\begin{array}{l}\text { Neurologic } \\
\text { effects }\end{array}$ & $\begin{array}{c}\text { Headache, seizure, vertigo, impaired } \\
\text { cognition }\end{array}$ \\
\hline $\begin{array}{l}\text { Ophthalmic } \\
\text { effects }\end{array}$ & Cataract, glaucoma, exophthalmos \\
\hline $\begin{array}{l}\text { Psychiatric } \\
\text { effects }\end{array}$ & Euphoria \\
\hline
\end{tabular}

prednisolone patient had increased the risk of infection, from which he is diagnosed with Pseudomonas aeruginosa. On decreasing the dose of prednisolone, decrease in the symptoms was observed then before. Despite everyday prednisolone, alternate day treatment is preferred which had showed a good response and symptoms such as facial edema, generalized edema, penile swelling and abdominal discomfort are decrease than before. Thus, it was confirmed that child had systemic toxicity due to prednisolone toxicity. On admission patient was diagnosed with relapse in known case of relapse of steroid sensitive nephrotic syndrome with signs of steroid toxicity with urinary tract infection and pre renal failure.

\section{CAUSALITIY ASSESSMENT}

WHO Scale: Probable

Naranjo's scale: Probable

\section{DISCUSSION}

In recent years, adverse drug reactions (ADRs) are identified as the major public health concern and they are considered to be one of the leading causes of morbidity and mortality among hospitalised patients. Proper patient counselling and effective monitoring of ADRs is required as there is increased usage of prednisolone medication. Prednisolone is a corticosteroid used in the patients with Nephrotic syndrome. In pediatric patient, during the first episodes of Nephrotic syndrome longer courses of prednisolone do not reduce the risk of relapse. It is used to induce remission in Nephrotic syndrome. ${ }^{3}$ Weight gain, edema, growth retardation and infection susceptibility chances are the ADR'S involved with the treatment.

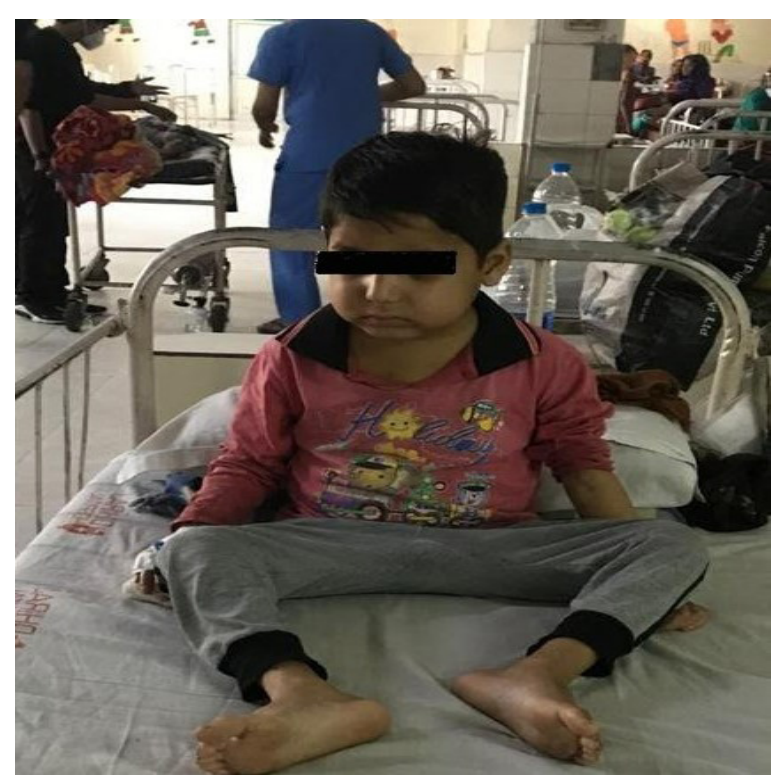

Figure 1: Patient with Facial edema. 
Prednisolone is more preferred on alternate day basis as it has shown improvement in the patient's condition and it also found that has shown clear decrease in long term adverse effects during the therapy. ${ }^{4}$ Proper monitoring of the drug and its side effects are necessary for the ADR management. So, it is necessary to monitor the child who is prescribed with prednisolone and routine laboratory check-up is mandatory.

\section{CONCLUSION}

Proper counselling is necessary for the implementation of treatment and effective outcomes. Dose tapering should be done and followed upon. Close monitoring of the adverse effect if any, and the possible safety should be taken care off with careful monitoring. This also implies wide role of clinical pharmacist which is needed for therapeutic evaluation.

\section{ACKNOWLEDGEMENT}

The Authors would like to thank the Department of Pharmacy, Sumandeep Vidyapeeth University, Vadodara, Gujarat, India.

\section{CONFLICT OF INTREST}

The authors declare that they have no conflict of interest.

\section{ABBREVIATIONS}

ADR: adverse drug reaction; FDA: food and drug administration; BSA: body surface area; B/L: bilateral.

\section{REFERENCES}

1. Prednisolone. IBM Micromedex. Available from [internet] [cited Feb 25, 2021]. Available from: https://www.micromedexsolutions. com/micromedex2/librarian/CS/8C505F/ND_PR/evidencexpert/ ND__Plevidencexpert/DUPLICATIONSHIELDSYNC/BCFC33/ ND_PG/evidencexpert/ND_B/evidencexpert/ND_AppProduct/ evidencexpert/ND_T/evidencexpert/PFActionId/evidencexpert. DolntegratedSearch?SearchTerm=Prednisolone\&fromInterSaltBase=true \& UserMdxSearchTerm=\%24userMdxSearchTerm\&false=null\&=null\#.

2. Liu D, Ahmet A, Ward L, Krishnamoorthy P, Mandelcorn ED, Leigh R, Brown $\mathrm{JP}$, Cohen A, Kim H. A practical guide to the monitoring and management of the complications of systemic corticosteroid therapy. Allergy Asthma Clin Immunol. 2013;9(1):30. doi: 10.1186/1710-1492-9-30, PMID 23947590.

3. Hahn D, Hodson EM, Willis NS, Craig JC. Corticosteroid therapy for nephrotic syndrome in children. Cochrane Database Syst Rev. 2015;(3):CD001533. doi: 10.1002/14651858.CD001533.pub5. PMID 25785660.

4. Nephrotic syndrome in children - Scientific Figure on ResearchGate. Available from [internet] [cited Feb 21, 2021]. Available from: https://www.researchgate. net/figure/Management-of-childhood-nephrotic-syndrome- A-kidney-biopsy-isnot-necessary-before_fig2_7654802. 